\title{
A Self-Assessment of European Citizen Science Projects on Their Contribution to the UN Sustainable Development Goals (SDGs)
}

\author{
Nicola Moczek ${ }^{1,2, *}$, Silke L. Voigt-Heucke ${ }^{1,3}$, Kim G. Mortega $^{1}{ }^{1}$, Claudia Fabó Cartas ${ }^{1,4}$ and Jörn Knobloch ${ }^{1}$ \\ 1 Museum für Naturkunde, Science Programme Society and Nature, 10115 Berlin, Germany; \\ Silke.Voigt-Heucke@mfn.berlin (S.L.V.-H.); Kim.Mortega@mfn.berlin (K.G.M.); \\ Claudia.FaboCartas@mfn.berlin (C.F.C.); Joern.Knobloch@mfn.berlin (J.K.) \\ 2 PSY:PLAN Institute for Architectural and Environmental Psychology, 10245 Berlin, Germany \\ 3 Animal Behaviour, Institute of Biology, Freie Universität Berlin, 14195 Berlin, Germany \\ 4 European Citizen Science Association (ECSA), 10115 Berlin, Germany \\ * Correspondence: Nicola.Moczek@mfn.berlin
}

Citation: Moczek, N.; Voigt-Heucke, S.L.; Mortega, K.G.; Fabó Cartas, C.; Knobloch, J. A Self-Assessment of European Citizen Science Projects on Their Contribution to the UN Sustainable Development Goals (SDGs). Sustainability 2021, 13, 1774. https://doi.org/10.3390/su13041774

Academic Editors: Jordi Colomer Feliu and Marc A. Rosen

Received: 31 October 2020

Accepted: 27 January 2021

Published: 7 February 2021

Publisher's Note: MDPI stays neutral with regard to jurisdictional claims in published maps and institutional affiliations.

Copyright: (c) 2021 by the authors. Licensee MDPI, Basel, Switzerland. This article is an open access article distributed under the terms and conditions of the Creative Commons Attribution (CC BY) license (https:// creativecommons.org/licenses/by/ $4.0 /)$.

\begin{abstract}
In theoretical frameworks, it is often assumed that citizen science projects contribute to the Global Sustainable Development Goals (SDGs) because of their participatory character and the potential for social transformation. To bring a practical perspective into the dialogue, we designed a survey to obtain direct assessments of the contribution of citizen science to the SDGs by European project participants. We launched the survey across European science networks in 2020 and evaluated 125 questionnaires. Participants reported contributing most to three of the SDGs: 'Good health and well-being', 'Quality education', and Life on Land'. Additionally, our results provide evidence that, with ongoing advocacy, citizen science projects in Europe could support all SDGs in the future. Seventy-two percent of participants indicated that their projects are involved in data acquisition and $30 \%$ stated to report data, but $19 \%$ do not pass on data at all. Our findings indicate further that European citizen science projects lack infrastructures and institutional support to facilitate data sharing. We recommend a focus on the promotion or creation of interfaces, for example, between projects and UN databases. Finally, we advise that citizen science projects, some of which operate with little funding, should not be overburdened with inflated expectations as a means of implementing the SDGs.
\end{abstract}

Keywords: citizen science; public participation in science; sustainable development goals (SDGs); sustainability; SDG indicators; partnerships

\section{Introduction}

In theory, citizen science is considered to have great potential for achieving the Global Sustainable Development Goals (SDGs). The 17 SDGs are part of the United Nations "Agenda 2030 for Sustainable Development" e.g., [1-3]. To date, however, little empirical research has been undertaken to study how active participants of citizen science projects assess their contribution towards the achievement of the SDGs.

In preparation for the Citizen Science SDG conference 'Knowledge for Change: A decade of Citizen Science (2020-2030) in support of the SDGs' as an official event of Germany's 2020 EU Council presidency, the team of authors was confronted with multiple experiences, expectations, and perspectives. Therefore, we assumed some gaps between the theoretical or top-down demands for citizen science's support towards the SDGs and the current practical approach and contribution. Shulla et al. [4] also made this observation and captured all policy and social initiatives and approaches that address citizen science's contribution to the SDGs. They identified five collaboration channels in which citizen science can support the SDGs through their engagement in policy, education, multi-stakeholder partnerships, and data collection. The expectation of such a broad 
engagement for the SDGs in all these very complex fields of action attributes citizen science to a structural and organizational form that-in our opinion-it does not yet possess. We also came to this assessment because we have insight into over 150 citizen science projects since we operate the German citizen science platform [5], and we are in very close communication with the Austrian [6] and Swiss platforms [7] as well as with the European platform and their projects [8]. We also observe with certain concern that these expectations could lead to excessive demands and an overstraining of citizen science. Against this perspective, the goal of our study was to gain a better understanding of the actual contribution made by citizen science projects to global sustainability.

For the elaboration, we will extend existing approaches with our perspective. In terms of support of citizen science to the SDGs, we focus on three aspects. First, the fields of action in which citizen science projects can provide significant impetus for achieving the SDGs. Second, the current and potential contributions of citizen science towards the SDGs on the level of the goals and/or indicators. Third, data acquisition, data sharing, and complementing of traditional sources with data from citizen science projects. In the next sections, we will briefly present the theoretical framework to design our online survey.

(1) Fields of action: In one of the first publications on the topic, West and Pateman [1] suggested three fields of possible action: the definition of national and regional targets and metrics; monitoring progress through the collection, evaluation, and provision of data; and implementing measures. This first suggestion was a very helpful structure. The attribution of the role of citizen science projects as reliable data providers underestimates a second important function they provide. This function is to make citizens aware of relevant topics, to sensitize them to the issues and social challenges, and to act as a bridge to research and knowledge. This is the main message of Sauermann and colleagues in their article published at the end of April [9]. Moreover, 64\% of those 84 surveyed by Shulla et al. in 2020 named the lack of awareness of SDGs as a challenge [4]. Some might also take a critical stand towards the Agenda 2030 and the SDGs, which offers the opportunity to debate the goals among stakeholders [10]. From a more psychological point of view, we see another important field of action in enabling sustainable behavior and promoting citizen engagement. This function is emphasized in many publications, e.g., Shirk et al. (2012) [11]. The active involvement can "educate and inspire the participants, changing their attitudes and behaviors and even turning them into advocates or activists for a particular development challenge" [1]. In their competence model, Roczen et al. [12] argued that environmental knowledge only has a modest behavioral effect, but the attitude towards nature turned out to be the stronger determinant of behavior. Nevertheless, we should not forget that many participants start their engagement with a high level of awareness and positive attitudes towards the issues. Therefore, when evaluating such projects, the effects on changes in attitudes through participation could remain small as observed by Brossard et al. [13] and Moczek [14].

(2) Current and potential contributions to the SDGs: In 2020, Fraisl and her colleagues published a detailed analysis of the current and potential contributions of citizen science to the SDGs [2]. Their review of the metadata and work plans of a set of international citizen science projects supporting the 244 SDG indicators (as of 2017) showed that citizen science projects already contribute to five indicators. They identified further 76 indicators on which projects could provide valuable data. They see the greatest contributions being made to goal 15 (Life on land), goal 11 (Sustainable cities and communities), goal 3 (Good health and well-being), and goal 6 (Clean water and sanitation). Shortly after in 2020, Schleicher and Schmidt analyzed 127 citizen science projects presented on the German citizen science-platform (as of June 2019) [15]. They developed a category system to identify how citizen science projects are connected to the SDGs. They show thematic references to 12 of the 17 goals. Goal 15 (Life on land) is also in first place in this study, with 48 thematically linked projects. In the second place, the authors see goal 4 (Quality education) with 33 projects, followed by goal 13 (Climate action) with 22 projects and goal 11 (Sustainable cities and communities) with 10 linked projects. 
(3) Data acquisition and sharing: A team led by Steffen Fritz focused on the special role of data [3]. Among other things, they stated that traditional data sources for reviewing sustainability goals (e.g., collected by national statistical offices) are often insufficient. In addition, due to the high costs of data acquisition, these data are often only rarely available with regard to temporal, spatial, and factual aspects. Therefore, they could be usefully supplemented on a finer level with data from citizen science projects. Concentrating on biodiversity research, Theobald et al. (2015) [16] detected in their review that citizen science projects gather data on a fine-grain-level, that they achieve datasets reaching local, regional and even global scales, and long temporal extents. Their findings suggest that voluntary projects span spatial scales that are comparable to professional scientists and last, on average, 7 years longer than the mean length of funded projects. However, they also revealed that only $12 \%$ of reviewed projects listed peer-reviewed scientific publications and they deduce that much of the data is still undiscovered and cannot yet be used by others [16]. In societal fields, this kind of local-based defined and collected data could be particularly important in the context of marginalized groups, whose situation may not be well captured by targets or statistics designed for the mainstream population [1].

In summary, we note that these findings provide very valuable analyses, but we miss empirical data and/or information stemming from the projects themselves. To gather the assessments and practical experiences of citizen science projects, we designed a pilot study that brings their perspectives into the scientific discourse.

\section{Research Questions}

This present study should extend our knowledge from the more theoretical analyses of the contribution of citizen science projects to support the SDGs to the self-assessment of the protagonists. The following research questions guided us:

1. What are the fields of action citizen science projects are working in? As a result of our research, we now present a new structure with five fields of action: raising awareness, defining, monitoring, implementing, and acting.

2. To which of the 17 SDGs do the projects contribute? For our survey, we assumed that a detailed query on the level of the then 244 indicators [2] would not be feasible for two reasons. On the one hand, we also wanted to address projects that have had little connections to the SDGs so far and a query on the indicator level would have been too specific. On the other hand, this would have significantly extended the processing of the questionnaire for the more experienced projects. We therefore stayed at the goal level and asked for current and future support for each goal separately.

3. Where are data collected in the projects being published and to which databases are the data transferred? In our study, we aimed to better understand if and how projects share their data and publish their findings and experiences.

4. In which areas do the projects want further assistance to support the SDGs with their citizen science projects?

5. How do the participants currently assess the effects of citizen science in their country?

In addition to the aim of answering the research questions, we were aware of the opportunity to use such a survey to create a sort of public interest and to draw attention to the SDGs. Therefore, the survey had also the character of an intervention. Through the nature of our anonymous questionnaire, we wanted to stimulate the European projects to reflect on their own activities and to motivate them to openly state their need for assistance.

\section{Methodology}

\subsection{Online Questionnaire Design}

We divided the questionnaire into three subsections. Most of the questions had a closed response format but, in addition, we also presented some open formats to get deeper and more personal insights into the work of the projects.

(1) In the first subsection, we posed questions on aspects of the organizational framework of the projects and asked for descriptive facts of our sample. We started with the 
country of research (a list of 55 countries was presented, multiple choice) and six project phases following the categories of the EU-Citizen.Science platform [8] (not yet started, active, periodically active, on hold, completed, abandoned). As for the initiators of the projects, respondents could choose between nine options (multiple choice: research society; research institute, university, college; school, educational institution; authority (municipality, federal or state); private person(s); business (commercial economy); local and citizen associations, civil society groups, non-governmental organizations; and media). Moreover, we asked for the role of the respondents in the project in order to distinguish between people who are active in the project, either on a job or as a volunteer (multiple choice; three roles: professional (e.g., as a scientist in a paid job); volunteer as a citizen scientist; and/or supporter (financial backer, evaluator, consultant, authorities representative, etc.). We also inquired to which topics the projects assigned and offered a list of 29 topics as possible answers again following the ones of the EU-Citizen.Science platform [8].

Following Shirks framework for Public Participation in Scientific Research [11], we asked what roles do citizen scientists undertake in the projects and presented contributors (primarily of data), collaborators (active involvement in some phases of the research), cocreators (active involvement in most or all phases of the research) as three of the possible answers. As a replacement for the role colleagues, we offered the additional three options: supporters (e.g., by providing rooms, material, or technology), project leaders, and initiators. We did not ask for any personal or project related information that would allow identifying the projects or the respondents.

(2) In the second subsection, we asked if the respondents were familiar with the notion of the SDGs (four options: No never; I am not sure; Yes, but do not know much about it yet; and Yes, they are familiar to me). We proposed five fields of action to select from together with a short definition: raising awareness (recognizing problems, informing and publishing, sensitizing), defining (set goals or new indicators), monitoring (collecting, processing, and making data available), implementing (implement concrete measures, create offers, solve problems), and acting (enable sustainable behavior of people, promote engagement, etc.). For each of these five fields of action, we asked for examples from concrete project work in an open format. Due to the very high number of mentions (395; see Table 4), we have not yet been able to conduct an in-depth qualitative data analysis. Therefore, two colleagues examined the data through a simple content analysis.

In the key section of our survey, we introduced all 17 SDGs. Participants could choose which ones their citizen science project already actively contribute to (first part of the question) or to which ones their project could contribute in the future (second part of the question). After this, we presented a list containing five different types of open access publications, and in addition, the option not open access and I don't know to get more information about where research data is published (multiple selection possible). For a more detailed analysis of the project's data sharing, we enquired if participants shared their project's data with one or more UN databases. We displayed a list of 19 databases such as the World Health Organization, United Nations Office on Drugs and Crime, UN Children's Fund, Food and Agriculture Organization of the UN, and the World Bank as possible answers. As an alternative, the respondents could indicate that they share their data with their authorities (municipality, federal, or state), that they do not pass on any data, or that they do not know about the sharing of data.

In the last question of this subsection, we asked for what purpose the projects would like to get assistance and again presented the five fields of action plus a statement on data reporting. We framed the presented fields with the sentence beginning "I would like to get assistance how to ..." ", to obtain a more personal assessment.

(3) In the third subsection, we asked for a personal rating of the current effects of citizen science in their countries. We presented ten statements and asked participants to express their rating in per cent. Therefore, we provided an 11-point-scale starting from $1=0$ Percent to $11=100$ Percent. 


\subsection{Distribution, Period, and Evaluation}

The survey was developed in preparation for the Citizen Science SDG conference 'Knowledge for Change: A decade of Citizen Science (2020-2030) in support of the SDGs', organized by the Museum für Naturkunde Berlin (Germany) on 14-15 October 2020, as an official event of Germany's 2020 EU Council presidency [17]. The questionnaire was designed using the software survey tool SoSciSurvey (SoSci Survey GmbH, Munich, Germany) and was open from 29 July until 12 October 2020 [18]. We aimed to address mainly European projects about their experiences, as this was in line with the orientation of the conference. We presented an English and a German version. The survey was widely advertized through various communication channels, such as the CS-SDG conference newsletter, the official twitter account of the conference, and via partner organizations working in the field of citizen science and the SDGs. The most successful were the newsletter of the conference, and the European Commission's and the European Citizen Science Association (ECSA) mailing lists.

In total, we received 195 responses. Due to a lack of consent to data storage $(n=2)$ or incomplete records $(n=68), 125$ responses could ultimately be included in the analysis. The incomplete records had no data at all and we therefore assume that colleagues simply clicked through the questionnaire without giving any answers. All survey data were analyzed through simple descriptive statistics in order to summarize and combine the collected information. To support our findings, we used quotes from open question areas to represent real and practical experiences or concerns of the respondents.

\subsection{Sample}

Out of the 125 cases, $76 \%$ of the participants of the survey answered the English and $24 \%$ the German version. The majority of projects implement their research in one country $(92 ; 73.6 \%)$, another 10 projects in two countries $(8.0 \%)$, and a further 11 in three to six countries $(8.8 \%)$. Five projects took place across Europe, and others were working outside of Europe through corresponding partnerships: 11 projects conducted research with citizens in Africa, four projects from Kenya. Seven projects took place in Asia and South America each. Five projects are carried out worldwide (see Figure 1 for Europe).

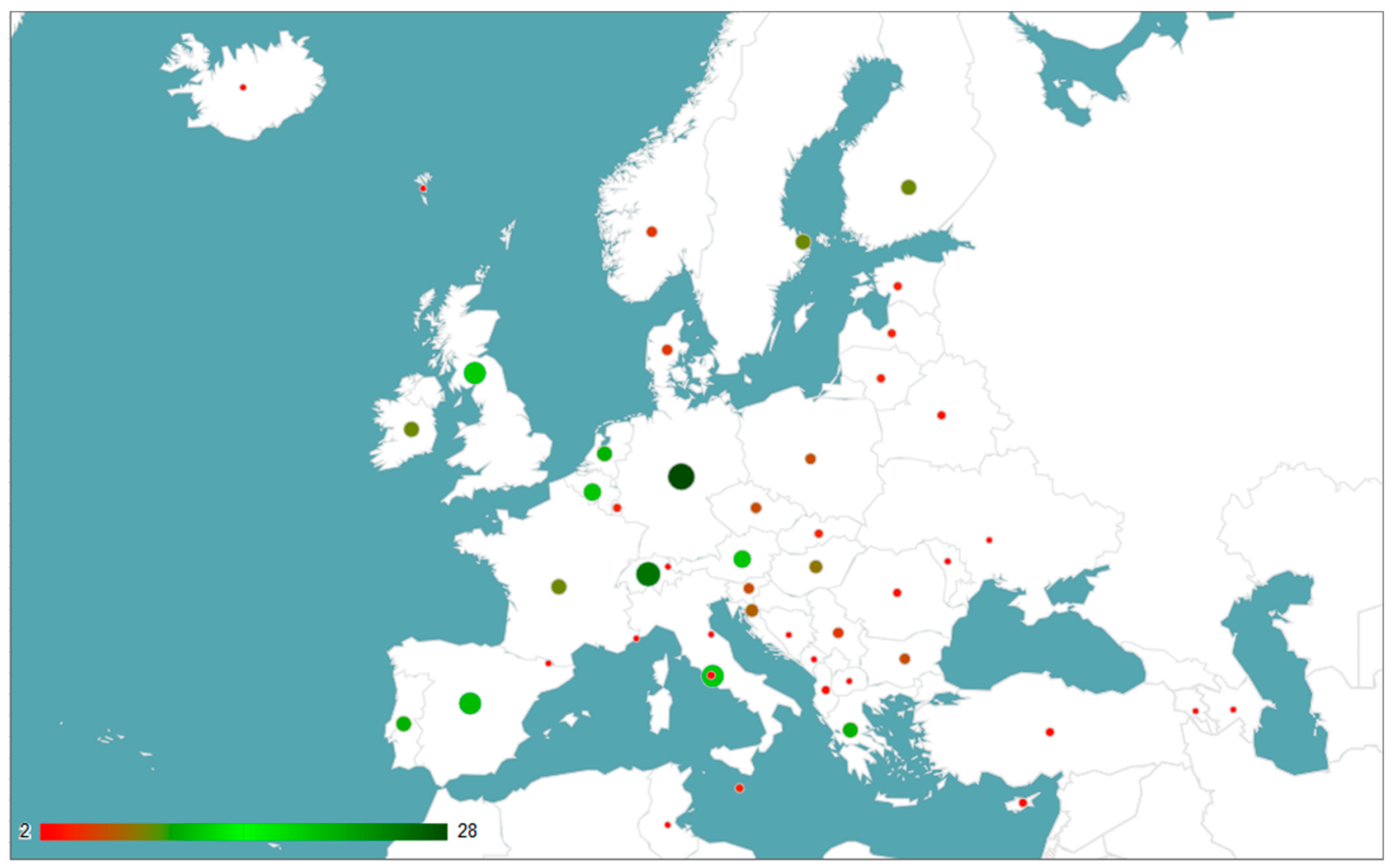

Figure 1. A representation of the European countries in which the citizen science projects participating in the survey are active $(\mathrm{N}=125)$. The greener and larger the color dots, the more projects participated from the country. 
Further, $78.8 \%$ of the survey participants were involved in the respective projects as professionals (e.g., as a scientist as part of a paid job), and $19.5 \%$ volunteer as a citizen scientist. Additionally, 8.5\% were supporters (financial backer, evaluator, consultant, authorities' representative, etc.). A large majority had heard of the SDGs before (75.2\%), another $20.0 \%$ had heard about the SDGs but did not know much about them yet. Very few participants were unsure what the SDGs were $(3.8 \%)$ or had never heard of them before $(1.0 \%)$.

The majority of the projects were started by one initiator (65.3\%). An additional $21.2 \%$ of projects were started by two, $5.9 \%$ by three, $2.5 \%$ by four, and $0.6 \%$ by six initiators. Further, $81.4 \%$ of the projects were initiated by scientific institutions- $-43.2 \%$ by universities or colleges, $34.7 \%$ by research institutes, and a further $3.4 \%$ by research societies-and civil actors initiated $59.3 \%$ of the projects. In addition, $23.7 \%$ of the projects were started by local or citizens' initiatives, civil society groups and non-governmental organizations and associations, and $15.3 \%$ by private individuals. Authorities (municipality, federal, or state) initiated $9.3 \%$ of the projects, business $6.8 \%$, schools or educational institutions $3.4 \%$, and media $0.8 \%$ (see Table 1 ).

Table 1. Initiators of the citizen science projects according to citizen science participants in the survey.

\begin{tabular}{cccc}
\hline & Frequency & Percent & Category \\
\hline University, college & 51 & 43.2 & science \\
Research institute & 41 & 34.7 & science \\
Local and citizen associations, civil society groups, NGOs & 28 & 23.7 & civil \\
Private person(s) & 18 & 15.3 & civil \\
Authority (municipality, federal or state) & 11 & 9.3 & civil \\
Business (commercial economy) & 8 & 6.8 & civil \\
School, educational institution & 4 & 3.4 & civil \\
Research society & 4 & 3.4 & cience \\
Media & 1 & 0.8 & civil \\
\hline
\end{tabular}

$n=118$. Multiple selection possible.

Most projects were in their active phase (65.6\%), 17.6\% had not yet started, $6.4 \%$ were periodically active, $3.2 \%$ of projects were already completed, and $2.4 \%$ of projects were on hold.

The roles that citizen scientists undertook in the projects are as collaborators $(70.8 \%)$, project leaders $(57.5 \%)$, initiators $(35.4 \%)$, supporters $(32.7 \%)$, contributors primarily of data $(13.3 \%)$, and co-creators ( $12.4 \%$; see Table 2$)$.

Table 2. Roles that citizen scientists undertake in the respective projects.

\begin{tabular}{|c|c|c|}
\hline & Frequency & Percent \\
\hline Collaborators * & 80 & 70.8 \\
\hline Project leaders & 65 & 57.5 \\
\hline Initiators & 40 & 35.4 \\
\hline Supporters & 37 & 32.7 \\
\hline $\begin{array}{c}\text { Contributors (primarily of } \\
\text { data)* }\end{array}$ & 15 & 13.3 \\
\hline \multirow[t]{2}{*}{ Co-Creators * } & 14 & 12.4 \\
\hline & 251 & 222.1 \\
\hline
\end{tabular}

In the survey, the selection of presented topics to which the projects could be assigned followed the list of the EU-Citizen.Science platform [8]. In a second step, we categorized them on a higher level (see Table 3 and Supplementary Materials). The majority of the projects conducted their research in the fields of natural sciences $(62.7 \%)$, social and hu- 
man sciences $(13.3 \%)$, and cultural sciences and humanities (13.0\%; multiple selection was possible).

Table 3. Categorized research areas as identified by the citizen scientists that took part in the survey.

\begin{tabular}{ccc}
\hline & Frequency & Percent \\
\hline Natural sciences & 222 & 62.7 \\
Social and human sciences & 47 & 13.3 \\
Cultural sciences and humanities & 46 & 13.0 \\
Engineering and planning sciences & 22 & 6.2 \\
Mathematics and computer science & 15 & 4.2 \\
Jurisprudence & 1 & 0.3 \\
Economics & 1 & 0.3 \\
\hline
\end{tabular}

$\overline{\mathrm{N}}$ = 125; multiple selection possible; mean of selected options 2.8; percent calculated on the selected options.

\section{Results}

This section focuses on the results of five themes within the action areas, current and expected support for each SDG, sharing of data, various demands for support, and personal assessment of the impact of citizen science.

\subsection{Fields of Action}

We enquired about the field(s) of action to which the citizen science projects estimated their contribution towards the SDGs. As Figure 2 shows, $72.0 \%$ of the respondents work in the field of monitoring (collecting, processing, and making data available; see Table A1 in Appendix A). Followed by $66.4 \%$ which raise awareness (i.e., recognizing problems, informing and publishing, sensitizing); $43.3 \%$ in the field of acting (enable sustainable behavior of people, promote engagement, etc.); and a smaller percentage of $25.4 \%$ is involved in the implementation of concrete measures (and creating offers, solving problems, etc.). A percentage of 17.6 sees its contribution in the field of defining (set goals or new indicators).

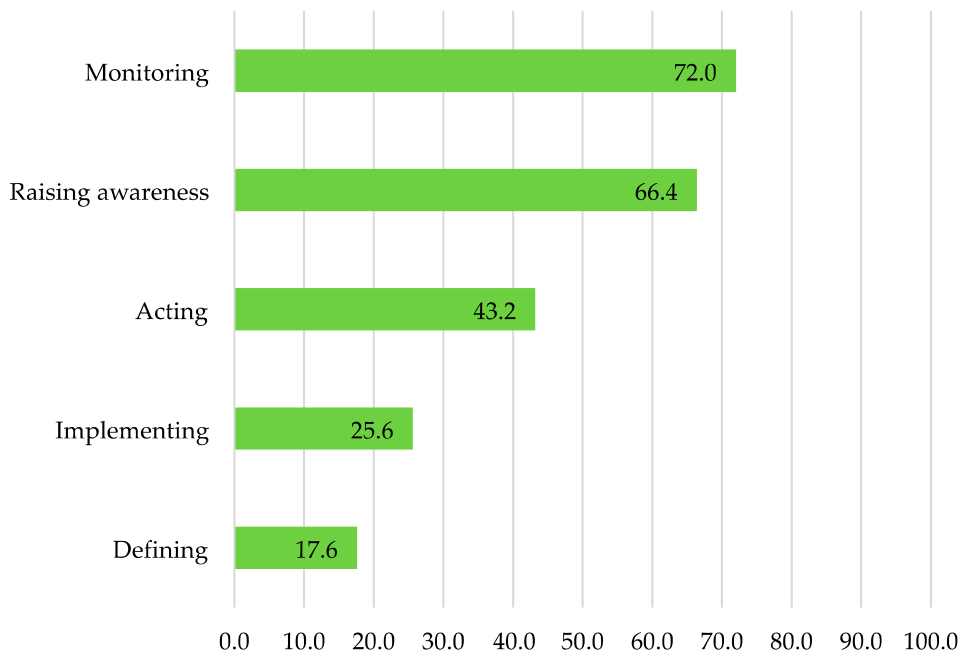

Figure 2. The percentage of fields of action as identified by citizen science participants that took part in the survey.

When we asked for concrete examples from everyday project work in the five fields of action, we received 395 mentions from 124 respondents (see Table 4). The participants assigned the examples to the fields of action themselves. We were not yet able to conduct an in-depth qualitative data analysis. Therefore, we present only five quotes in each area to give a first impression. A broad selection of quotes is presented in order to reflect the diversity of the answers submitted. 
Table 4. Exemplary quotations from respondents on their contribution to the five different fields of action.

\begin{tabular}{|c|c|c|}
\hline $\begin{array}{l}\text { Open Questions Regarding the } \\
\text { Fields of Action }\end{array}$ & $\begin{array}{l}\text { Number of Examples (by } \\
\text { Number of Respondents) }\end{array}$ & Selected Quotes \\
\hline $\begin{array}{l}\text { Raising awareness: Please give one } \\
\text { or more examples of how your project } \\
\text { is raising awareness for the relevant } \\
\text { topic. For example, by information } \\
\text { campaigns, talks, field trips. }\end{array}$ & $\begin{array}{l}167 \\
(68)\end{array}$ & $\begin{array}{l}\text { - "Interactive web map to show what pedestrians } \\
\text { say about street safety, comfort, pleasantness, and } \\
\text { vibrancy (including images)." } \\
\text { "We created a moving exhibition that can be locally } \\
\text { produced and exhibited to raise awareness." } \\
\text { "Through working with a partner organization } \\
\text { that is a key community center." } \\
\text { "Plastic entering the ocean is expected to increase } \\
\text { from } 900 \text { tons an hour in } 2010 \text { to } 4000 \text { tons an hour } \\
\text { by } 2030 . \text { We are removing the invisibility of litter } \\
\text { that many people have become accustomed to." } \\
\text { "We will start a series of online or f2f talks next } \\
\text { year to present and discuss the outcomes that } \\
\text { emerge from the data collection." }\end{array}$ \\
\hline
\end{tabular}

- $\quad$ "We provide qualitative data to help moving from quantitative indicators to mixed ones."

- "We provide data at finer spatial and temporal scales on air quality."

- $\quad$ "We provide positive data re: quiet areas and suggest adding positive indicators rather than only

Defining: The SDG indicator

framework is a work in progress.

Please give one or more examples of how definitions are worked on in your project. For example, provide data at finer spatial and temporal scales to support SDG-indicators. negative ones (i.e., in the SDGs there is only noise as an indicator). This is in line with the WHO that recommends reducing noise while protecting quiet areas (WHO 2018)."

- "Provide deeper insights into road safety (target 3.6) for vulnerable user by adding information about pedestrian experiences (i.e., near miss accidents that are not reported by official data)."

- " "...We have provided input to the monitoring methodology for SDG 6.3.2 in the past, highlighting here capacity challenges in water quality monitoring and the role of citizen science in addressing these challenges."

- “ “Urban walk with elderly people to collect data on air quality linked with their perception of pollution."

- "Co-create interventions to understand what participants are doing to stay happy and healthy during the pandemic."

Monitoring: Please give one or more examples of the different methods used in your project in order for you to collect different types of data. For example, online platform to collect bird observations (pictures, sounds).
- "Tool to collect images/photos of aspects of the local urban environment that enables people to be healthy."

- "App and website to crowdsource earthquake detection, visual images to collect earthquake intensities, use of Twitter to automatically detect earthquakes."

- "Motion-sensing camera traps for in-situ wildlife photos." 
Table 4. Cont.

\begin{tabular}{|c|c|c|}
\hline $\begin{array}{c}\text { Open Questions Regarding the } \\
\text { Fields of Action }\end{array}$ & $\begin{array}{l}\text { Number of Examples (by } \\
\text { Number of Respondents) }\end{array}$ & Selected Quotes \\
\hline $\begin{array}{l}\text { Implementing: Please give one or } \\
\text { more examples of how concrete } \\
\text { measures and offers are implemented } \\
\text { in your project. For example, organize } \\
\text { a weekly market with regional } \\
\text { products to promote sustainable } \\
\text { consumption. }\end{array}$ & $\begin{array}{l}34 \\
(24)\end{array}$ & $\begin{array}{l}\text { - } \quad \text { "Free workshops and online seminars for different } \\
\text { target groups." } \\
\text { "Offering tools and guidelines on how to make } \\
\text { - } \quad \text { "Affordable precision agriculture tools for } \\
\text { smallholders farmers." } \\
\text { "Organization of workshop for people willing to } \\
\text { contribute their own instruments, to help them } \\
\text { build it." } \\
\text { "Workshop with local stakeholders and policy } \\
\text { makers to facilitate change." }\end{array}$ \\
\hline $\begin{array}{l}\text { Acting: Please give one or more } \\
\text { examples of how people are } \\
\text { encouraged to commit to and behave } \\
\text { in sustainable ways in your project. } \\
\text { For example, teach and encourage } \\
\text { people to use sustainable forms of } \\
\text { transport. }\end{array}$ & $\begin{array}{c}61 \\
(40)\end{array}$ & $\begin{array}{l}\text { - } \quad \text { "Collectively decide the most needed actions in } \\
\text { "Lental health care." } \\
\text { health, wellbeing, the environment, and the } \\
\text { economy; and the importance of creating and } \\
\text { protecting quiet areas on a local scale that are } \\
\text { accessible to everyone in our society." } \\
\text { "Promote more walking (modal shift from car to } \\
\text { walking for short trips) with the creation of } \\
\text { updated and reliable information (street signage } \\
\text { linked to online maps) about walking routes in } \\
\text { urban areas." } \\
\text { "Participants will receive direct feedback on their } \\
\text { choice of food, and climate impact of any food } \\
\text { wasted. This will show how different food } \\
\text { consumption (and amounts of waste) impacts } \\
\text { environmental aspects such as water usage and } \\
\text { climate change" } \\
\text { "No need. Those who decide to join already } \\
\text { behave in sustainable ways." }\end{array}$ \\
\hline
\end{tabular}

$\begin{array}{lc}\text { Sum of examples (by number of } & 395 \\ \text { respondents in total) } & (124)\end{array}$

\subsection{Current and Future Support of the SDGs}

In the survey, participants were first asked about their current support of the 17 SDGs (see Figure 3; green bars; results in per cent) and second, about their future support (blue bars). All 17 SDGs are currently getting support through the projects surveyed. In addition, $25.6 \%$ of the projects indicated that their research currently supports SDG 3 'Good health and well-being'; followed by SDG 4 'Quality education' (24.0\%) and SDG 15 'Life on land' $(21.6 \%)$.

Regarding the assumed potential for future support, again, SDG 3 'Good health and well-being' is listed first place as well as SDG 11 'Sustainable cities and communities' both with $23.2 \%$; followed by SDG 13 'Climate action' (22.4\%), SDG 5 'Gender equality' (21.6\%), and SDG 4 'Quality education' (20.0\%).

We have summarized the results of current and future support, and the overall ranking reads as following: SDG 3 'Good health and well-being', SDG 4 'Quality education', SDG 11 'Sustainable cities and communities', SDG 13 'Climate action', and on fifth place SDG 15 'Life on land'. These results are partly surprising because previous research has so far seen the main support of citizen science towards SDG 15 'Life on land'. However, the poorest support could be found in support of social and economic goals such as SDG 2 
'Zero hunger' (4.8\%) or SDG 1 'No poverty' (1.6\%). The potential support was estimated higher, but the shares remained small. The potential support for SDGs 8, 1, and 7 were $8 \%$ each.

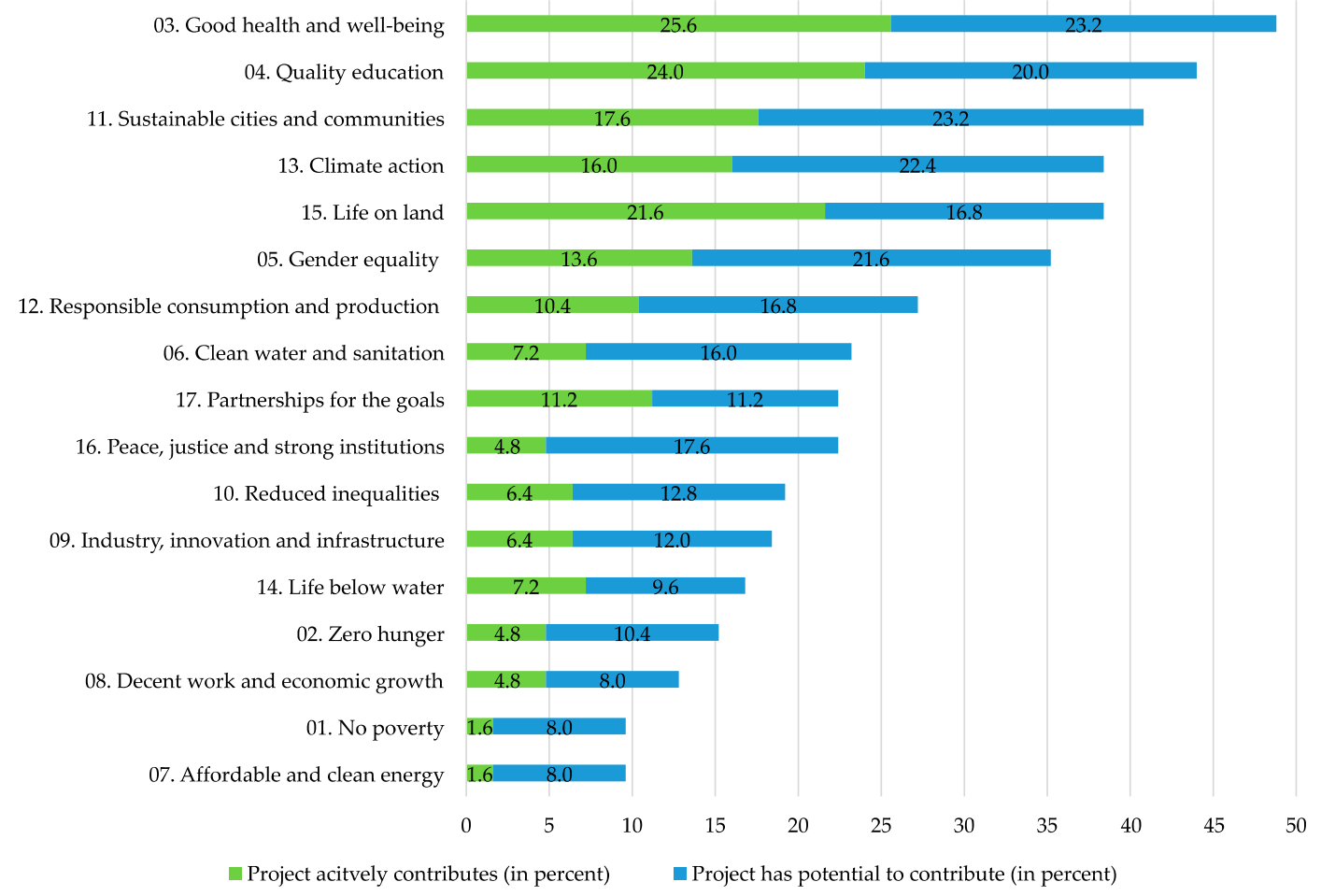

Figure 3. Current and future support of the Global Sustainable Development Goals (SDGs). In green are the percentages of citizen science projects surveyed that have indicated that they are already contributing to the SDGs. In blue are the percentages of the potential contribution from the projects in the future.

\subsection{Data Reporting and Publishing in Support of the SDGs}

On that issue, we presented two questions in a closed response format. First, we wanted to know if the respondents share their project's data with one or more of the United Nations' databases. The majority of respondents (43.1\%) indicated that they do not know it, $29.5 \%$ share their data with authorities, and $19.3 \%$ reported that they do not pass on any data. Only one respondent reports its data to the UNEP (UN Environment Programme).

Second, we aimed to find out if and where the research data collected in the respective citizen science projects were already (or will be) published. We focused on the comparison of open access and not open access, and presented a variety of open access formats (see Table 5). Again, we offered the option 'I don't know'. In total, 56.8\% of the participants use open access to publish their data; $8.0 \%$ do not. Of the presented open access formats, the publicly accessible databases are used by $38.6 \%$ of respondents; online accessible maps or similar are used by $33.0 \%$; independent research data publications by $15.9 \%$; and preprint servers by $3.4 \%$. 
Table 5. Data publishing in open and not open access formats.

\begin{tabular}{ccc}
\hline & Frequencies & Percent \\
\hline I don't know & 11 & 12.5 \\
Not open access & 7 & 8.0 \\
\hline Open access & 50 & 56.8 \\
Publicly accessible database & 34 & 38.6 \\
Data points on an online accessible map or similar & 29 & 33.0 \\
Independent research data publication & 14 & 15.9 \\
(on a repository, via GitHub or similar) & 3 & 3.4 \\
Preprint server (arXiv or similar) & &
\end{tabular}

$n=88$; multiple selection possible.

\subsection{Request for Assistance in the Five Fields of Action}

In the next step, we asked in which field(s) the respondents would like to get assistance in order to support the SDGs with their citizen science projects (see Table 6). In line with the results of the previous questions regarding the reporting of data, about half of the respondents $(54.5 \%)$ showed an interest for assistance to contribute to data collection, monitoring and analysis that is useful for the SDGs. $49.5 \%$ of respondents indicated that they would like to get assistance to report data to responsible authorities and/or United Nations databases; and 31.3\% would need further support to define SDG-goals and SDG-indicators. $37.4 \%$ indicated a need for assistance to enable engagement and promote sustainable behavior. $35.4 \%$ of the respondents wished to get support to take action and implement sustainable measures and $27.3 \%$ to raise awareness of the SDGs.

Table 6. Request for assistance in the five fields of action in order to support the SDGs as indicated by citizen science participants that took part in the survey.

\begin{tabular}{lcc}
\hline \multicolumn{1}{c}{ I Would Like to Get Assistance How to ... } & Frequencies & Percent \\
\hline Contribute to data collection, monitoring, and analysis that is useful for the SDGs & 54 & 54.5 \\
Report data to responsible authorities and/or United Nations databases & 49 & 49.5 \\
Enable engagement and promote sustainable behavior & 37 & 37.4 \\
Take action and implement sustainable measures & 35 & 35.4 \\
Help to define SDG-goals and -indicators & 31 & 31.3 \\
Raise awareness of the SDGs & 27 & 27.3 \\
\hline
\end{tabular}

$n=99 ;$ multiple selection possible.

\subsection{Assessment of the Effects of Citizen Science in the Involved Countries}

The final question of our survey focused on the participants' rating regarding the effects of citizen science in their country (see Figure 4, and Table A2 in Appendix A). Overall, the respondents rate the current effects rather low but we see a great variance between the respondents. Looking at the mean values, we see the maximum rating for the 'variety of citizen science activities available to the public' (M 5.5; SD 3.9) and the lowest rating for 'identifying new scientific questions through co-operation with citizens' (M 2.9; SD 4.5).

An interesting point is the different share of knowledge transfer from science to citizens (M 5.1; SD 3.5) compared with the knowledge transfer from citizens to science (M 3.7; SD 3.3). Together with the effect of citizen science on the acceptance of science on the part of citizens (M 5.1; SD 4.8), the respondents evaluate the contribution of citizen science to the public communication of science rather positively. Contrary to this kind of relation, the respondents have a sceptical view on the effect of citizen science in the academic science such as the assessment of the statement 'identifying new scientific questions through cooperation with citizens' shows (M 2.9; SD 4.5). In addition, the 'impulses of citizen science projects in the respondents' country for changes towards sustainability' is low-rated with M 3.4. (SD 4.7). 
As described in our sample, we can distinguish between different groups of respondents. Regarding the assessment, we compared the rating of citizen scientists $(n=12)$ and scientists $(n=64)$. Since the group sizes differ so greatly, we dispense with an inferential statistical analysis. Even the descriptive comparison of the mean values shows no differences between the two groups. However, the standard deviations differ slightly; the variance of the answers was higher in the group of citizen scientists.
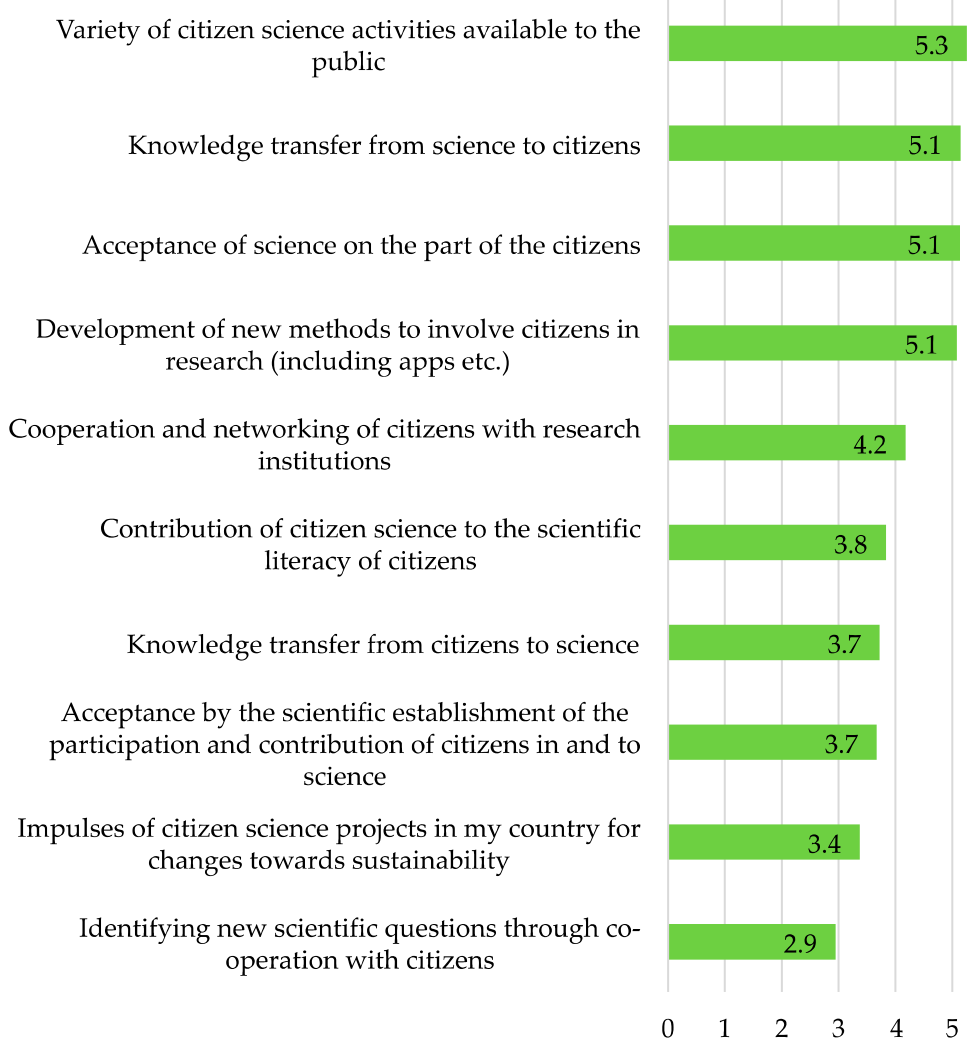

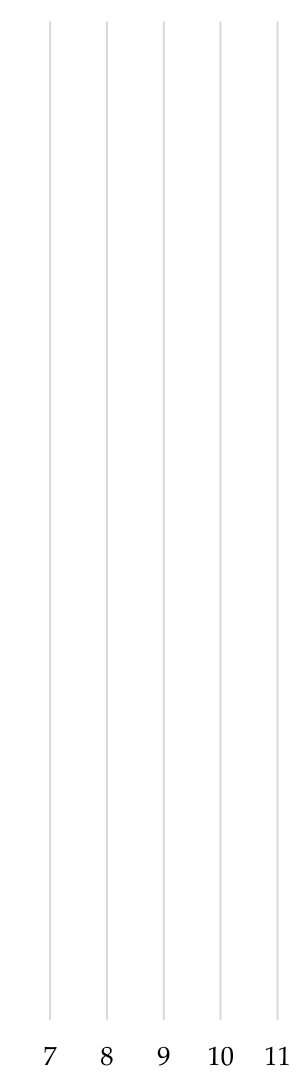

Figure 4. Mean values of personal assessments of the effects of citizen science in the involved countries; 11-point scale starting from $1=0$ Percent to $11=100$ Percent. $n=97$.

\section{Discussion}

Since innovation policy is framed by the goal of a "transformative change" the search for new instruments is a challenge for policy actors [19]. While addressing this goal has been successfully formulated as a political agenda in the SDGs, the necessary reflection of "bridging between what is possible and what is desirable" is not complete [19]. According to Schot and Steinmueller, this reflection requires "individuals with capabilities for bridging social and scientific and technological domains" which "implies a re-orientation of education policy and, ultimately, a pedagogy that is consistent with the desired transition to more sustainable outcomes" [19]. Hence, the search for innovative solutions of such systemic reflection is indispensable for the development of sustainable policy instruments. These instruments must be embedded in a dynamic governance approach, which is not reducible to regulation but promotes the inclusive engagement in science policy as an open "space for experimentation, societal learning, public debate, deliberation, and negotiation" [19]. We started our research with a theoretically-based assumption that citizen science is a promising and sustainable policy instrument to implement the SDGs. Following this assumption, we wanted to test whether citizen science fulfilled the requirements of the governance of transformative change. Starting with the statement from recently published articles, one chance and demand of the contribution of citizen science is the limited provision and sharing of knowledge by traditional data sources e.g., [1-3]. While 
the implementation of the SDGs requires a constant, systematic, and differentiated regime of knowledge production, traditional producers such as academics or public data offices cannot provide the necessary data or knowledge. They provide little or no data sets at the local and regional level that were collected over a longer period of time and, in particular, take into account social characteristics [16].

Political demands for (more) societal participation in research are thus driven by the assumption that it will fill the knowledge deficit. Current experience with COVID19 has also shown that certain people and population groups can be systematically or unintentionally marginalized and excluded throughout the phases of the data value chain. This applies to all data processes and data-related use of results such as data identification, data acquisition, analysis, dissemination, and interpretation. In the current situation with the COVID-19 pandemic, marginalization and exclusion have serious consequences, including death [20]. Explorative studies about the possibilities and potential of citizen science need to clarify how citizen science can supplement the lack of data and knowledge bases and what kind of support citizen science needs to do so. We started from this perspective and focused on the self-assessment of citizen science participants to explore obstacles, but also to get specific recommendations for the support needed.

To the best of our knowledge, our survey was the second to invite project initiators, managers, and participants in Europe to assess the contribution of their citizen science projects to the achievement and implementation of the SDGs. In total, we reached 125 participants through various European networks who contributed to the survey. Given the limited runtime of our survey, we consider this a good sample. Around 3/4 of the participants answered the survey in English, but as many as 1/4 of the participants chose German as their language. This result shows that the German-speaking countries (Germany, Austria, and Switzerland) are already promoting citizen science as a valuable approach in research, and as a result, several active SDG-related projects are being carried out. In these countries, there are both existing citizen science networks and national platforms [5-8] that strengthen and support networks and facilitate knowledge transfer between citizens and science. As expected, a large proportion of the respondents were professionals, i.e., engaged in a citizen science project under an employment relationship. Nonetheless, almost $20 \%$ of the respondents indicated that they (also) volunteer in the field of citizen science.

Our results demonstrate that participants most frequently referred to five SDGs when assessing the current and future contribution of their projects. These are namely SDG 3 'Good health and well-being', SDG 4 Quality education, SDG 11 'Sustainable cities and communities', SDG 13 'Climate action', and SDG 15 'Life on land'. These results are partly surprising because previous theoretical reviews have so far seen the main support of citizen science to SDG 15 'Life on land' [2,3]. Schulla et al.'s survey [4], which was similar in some respects to our study, showed almost similar results to ours, and also followed the same trend presented by Salvia et al. (2019) [21].

Encouragingly, $72 \%$ of the participants in the survey responded that their projects were active in the field of data collection and around $30 \%$ stated that they report data to the authorities. Unfortunately, one-fifth of the projects do not share data and one-third of the respondents do not know what happens to their data. Thus, we can see a great uncertainty on this relevant topic and we identified a problematic gap between the importance of data as the main element of supporting the SDGs and the practice of sharing data. This is also reflected in the fact that more than half of the participants asked for more and better support on how to contribute to the data collection, monitoring, and analysis that will support the achievement of the SDGs.

This ambivalent estimation of the valuable state of citizen science data was also reflected in our data with regard to the publication practice. The dominant mode of publication in the surveyed citizen science projects is open access. However, the percentage of publications with a further edition, evaluation, or cataloguing is less. The reason is probably to be found in the public participatory character of citizen science. Citizen science does not need the formal rules of the academic publication system. However, it can be 
speculated that the lack of a further format of publications affects the finding, and thus the perception of the results. These findings are also in line with those of Theobald and colleagues [16] who proved that only $12 \%$ of the 388 projects they surveyed provide data to peer-reviewed scientific articles, even though a third of these projects have verifiable, standardized data that are accessible online.

On the other hand, we learned from the reports of the study's participants about their strong efforts to raise awareness, change behavior, and implement sustainable measures. To our understanding, these are elements of collective emancipatory practice and extremely important for achieving global sustainability e.g., [9]. Citizen science projects could also shape the direction of research towards societal needs. Ideally, participation in citizen science projects would strengthen citizens' trust in science and, through close cooperation, reduce possible tensions between traditional scientific research institutions and their civil society partners. Sustainable transformation can only succeed if the exchange of knowledge and experience is mutual and both groups learn from each other [1]. Hence, citizen science goes beyond the limits of academic science and this is particularly important for the SDGs. It is an active instrument, which simultaneously activates people to engage in politics. In this respect, citizen science fulfils the expectations of the new innovation policy because this approach meets the requirements of the governance of transformative change.

However, it is important to us that our results are interpreted with caution. We assume high self-selection, which was certainly influenced by our communication channels. Our results may be also affected by the fact that the citizen science community, among which we distributed the survey, has been established very recently. Citizen science projects of large environmental organizations may not feel historically part of this young community, but might rather relate to the voluntary biodiversity sector and therefore may not be well represented in our survey. In our study, participants have been able to share their personal opinion, which brings a new perspective to the discourse, but also possibly a subjective colouring in the assessment. We are aware that the lack of internationalization of the questionnaire, however, means that the concern is only reflected at the European and First World level.

Therefore, we regard it as a pilot study and recommend to carry out further and more extensive studies soon, and not only in Europe but also worldwide. The use of additional languages such as French and Spanish would result in broader participation from countries in South America and Africa. To address also the Asian countries, more translations should be considered in future surveys.

It would be worthwhile to further underpin our cross-sectional approach with casecontrol studies. It would be particularly interesting to investigate countries in which citizen science is not yet structurally driven, e.g., through national funding or citizen science platforms. We are aware too that the use of an online questionnaire primarily focusing on quantitative data can lead to a selective approach to people and thus exclude target groups that could be better reached through other (qualitative social science) methods such as interviews, group discussions, or systematic observations. To better understand the potential of citizen science projects and the self-assessment of this internationally, it is pivotal to hear and respond to the own voices of projects and project coordinators. The many examples given by the respondents for the fields of action illustrate the diversity of the projects. They are also evidence that the respondents have an interest in sharing and discussing their experiences with the community. Our simple data analysis initially presents only subjectively selected examples. However, as the dataset is publicly available, colleagues could do further categorization and analyses in the future.

These findings and personal assessments are quite encouraging and we acknowledge the commitment of the projects. As already put forward in the introduction, we would like to caution that citizen science projects might be overburdened. Without funding schemes and significant backing within research institutions, they will never be able to meet the high expectations placed on them: involving the public at eye level and with a high level of communication, high data quality, open data and their dissemination to relevant 
authorities, publications in peer-reviewed journals, and above all the democratization and transformation of science systems. On the other hand, the support must preserve their independence and the potential for social innovation, which is more likely to be found outside the inflexible and self-referential system of academia. Therefore, we also view our survey as a means of communication and thereby provide an opportunity for self-reflection by highlighting the SDGs. This reflection is necessary for a realistic approach that protects against disappointed expectations.

A realistic assessment is also supported by the further contextualization of our findings. The results of the survey at hand among European citizen science projects support our presumption that while there is great potential for supporting the SDGs through citizen science data, the infrastructure, and institutional support to promote an easy exchange of data are lacking. The United Nations already provides information on the development and implementation of an indicator framework for the follow-up and review of the 2030 Agenda for Sustainable Development [22]. We particularly recommend the UN to put a stronger emphasis on facilitating the development of new partnerships with citizen science projects, as the UN databases have the greatest potential in terms of benefiting from the large and interesting amounts of citizen science data. In addition to the United Nations, we see that other infrastructures and agencies could be much more proactive and forthcoming in seeking contact with citizen science projects. In our view, there is a need to create and promote interfaces to forward citizen science data to the relevant bodies for the SDG indicators. The responsibility here must not lie with regional civil initiatives that collect relevant scientific data, but rather corresponding state authorities should be obliged to collect the data and forward it to higher-level authorities. Some large-scale citizen science initiatives are well organized in this respect: one example is the Pan-European Common Bird Monitoring Scheme (PECBMS). Based on data from volunteers and coordinating organizations across Europe, bird-monitoring data for common farmland, common forest, and all common birds is collected and indicators are calculated for Europe, its different regions, as well as the EU, New, and Old EU states. It is thus possible to calculate very accurately the conservation status of many bird species and groups and to make evidencebased recommendations for their protection in the future. Such a professionalized, wellfunctioning example of a pan-European citizen project, could serve as a blueprint for up-scaling regional initiatives relevant to SDG implementation [23]. As an example of the expanded geographical scope of successful citizen science projects that might support the SDGs, we would like to highlight the 'Plastic Pirates' which was upscaled as part of the EU trio presidency of Germany, Portugal, and Slovenia under the motto "Europe tackles this task together". However, we do not know if and how the Plastic Pirates data will be used for the SDG indicators.

Finally, our research supports the still open evaluation of the new innovation policy of transformative change. This policy and its governance structure still has an experimental character and must constantly realign itself. The task of politics is presumably "to experiment and transform the existing set of relationships" [19]. Therefore, our study is a scientific accompanying research. In addition, the results of our survey were indirectly included in the CS SDG Declaration, which was collectively developed by many contributors in a bottom-up co-creation process in preparation for the Citizen Science SDG conference [17]. The three main recommendations are to harness the benefits of citizen science for the SDGs, to strengthen citizen science and its connections with other communities, and to strengthen future (citizen) science systems [17]. The bottom-up process of the preparation of the Declaration, its scientific reflection, as well as its communication through the conference could be understood as an experiment for a necessary "new policy practice" [19]. Its significant result is a realistic evaluation of the contribution of citizen science to the SDGs within a governance system of transformative change. It remains exciting to see how policymakers will react to this offer of coordination.

The question remains: Is transformative change "an overambitious goal" for research and innovation policy, like Schot and Steinmueller critically noted [19]? If we answered 
this question positively, then this could also reflect a divergence between the frame of transformative change and the policy instrument, which also may result in excessive demand for citizen science. We believe that with effective and adequate support, i.e., financially, structurally, and through academia, the potential of citizen science as a means to help implement the SDGs is given — but it should not be overburdened by an inflated set of expectations.

Supplementary Materials: The following are available online at a repository of the Museum für Naturkunde Berlin: CVS with raw data; Excel-document with the questionnaire, raw data, evaluated data, tables and figures for all questions: https://doi.naturkundemuseum.berlin/data/10.7479/ mzy9-wp90.

Author Contributions: Conceptualization, N.M., S.L.V.-H., K.G.M., C.F.C. and J.K.; methodology, N.M.; software, N.M. using SoSciSurvey.com; validation, formal analysis, data curation, N.M.; writing—original draft preparation, N.M.; writing—review and editing, N.M., S.L.V.-H., K.G.M., C.F.C. and J.K.; visualization, N.M.; project administration, S.L.V.-H. All authors have read and agreed to the published version of the manuscript.

Funding: K.G.M. and C.F.C. received funding from the European Union's Horizon 2020 research and innovation programme under grant agreement No. 101000014. The publication was funded by the Open Access Fund of the Leibniz Association.

Institutional Review Board Statement: Ethical review and approval were not required for this study, as we worked closely with the data protection officer to provide all participants with detailed information about the conditions. Only after agreeing to these, they could participate in the survey. Specifically, we informed that participation was voluntary, questions could be skipped, and participation in the study could be terminated at any time and information already stored could be completely deleted. All responses were anonymous. Publication of the results does not allow any conclusions to be drawn about the project or the individual. The data was stored in a database of the Museum für Naturkunde exclusively for research purposes. The survey software SoSciSurvey was developed and is operated by a German company. The server is located in Munich. All privacy settings were set restrictively.

Informed Consent Statement: Informed consent was obtained from all subjects involved in the study.

Data Availability Statement: The following are available online at a repository of the Museum für Naturkunde Berlin: CVS with raw data; Excel-document with the questionnaire, raw data, evaluated data, tables and figures for all questions: https://doi.naturkundemuseum.berlin/data/10.7479/ mzy9-wp90.

Acknowledgments: We would like to thank all participants of our study who contributed such valuable information and further thoughts. We sincerely thank Colombe Warin, Project Adviser of the European Commission (Research Executive Agency) and Linden Farrer, Policy Officer of the European Commission (Directorate-General for Research \& Innovation) for their valuable comments on the draft of the questionnaire and for the dissemination of the questionnaire through their contacts and newsletters. We would also like to thank all colleagues at the Museum, which helped to spread the news on our survey. A special thank goes to Maike Weißpflug who contributed to fruitful discussions on the design of the open format questions and to Sarah Darwin who supported the translation of the English version of the questionnaire.

Conflicts of Interest: The authors declare no conflict of interest. 


\section{Appendix A}

Table A1. Number of examples of fields of action.

\begin{tabular}{|c|c|c|c|c|c|c|c|}
\hline (Fields of Action) & & Awareness & Defining & Monitoring & Implementation & Acting & (Sum) \\
\hline Sum of aspects mentioned & & 167 & 19 & 114 & 34 & 61 & 395 \\
\hline \multirow{8}{*}{ Frequencies of aspects } & 7 & 3 & 0 & 0 & 0 & 0 & \\
\hline & 6 & 1 & 0 & 0 & 0 & 0 & \\
\hline & 5 & 4 & 0 & 2 & 0 & 0 & \\
\hline & 4 & 8 & 0 & 5 & 1 & 1 & \\
\hline & 3 & 10 & 0 & 7 & 0 & 8 & \\
\hline & 2 & 16 & 5 & 15 & 7 & 2 & \\
\hline & 1 & 26 & 9 & 33 & 16 & 29 & \\
\hline & 0 & 57 & 111 & 63 & 101 & 85 & \\
\hline Number of respondents & & 125 & 125 & 125 & 125 & 125 & \\
\hline
\end{tabular}

Table A2. Frequencies of personal assessments of the effects of citizen science in the involved countries.

\begin{tabular}{|c|c|c|c|c|c|c|c|c|c|c|c|c|c|}
\hline & \multicolumn{12}{|c|}{ Frequencies } & \multirow[b]{2}{*}{ SD } \\
\hline & $0 \%$ & $10 \%$ & $20 \%$ & $30 \%$ & $40 \%$ & $50 \%$ & $60 \%$ & $70 \%$ & $80 \%$ & $90 \%$ & $100 \%$ & $\mathbf{M}$ & \\
\hline & 0 & 4 & 17 & 10 & 20 & 11 & 11 & 8 & 4 & 1 & 1 & 2.9 & 4.5 \\
\hline $\begin{array}{l}\text { The impulses of citizen science projects in my } \\
\text { country for changes towards sustainability }\end{array}$ & 0 & 3 & 7 & 20 & 16 & 9 & 13 & 8 & 4 & 6 & 0 & 3.4 & 4.7 \\
\hline $\begin{array}{l}\text { The acceptance by the scientific establishment } \\
\text { of the participation and contribution of } \\
\text { citizens in and to science }\end{array}$ & 0 & 4 & 18 & 13 & 16 & 8 & 14 & 8 & 6 & 2 & 1 & 3.7 & 3.9 \\
\hline $\begin{array}{l}\text { The knowledge transfer from citizens } \\
\text { to science }\end{array}$ & 0 & 5 & 12 & 21 & 16 & 13 & 17 & 4 & 2 & 1 & 1 & 3.7 & 3.3 \\
\hline $\begin{array}{l}\text { The contribution of citizen science to the } \\
\text { scientific literacy of citizens }\end{array}$ & 0 & 5 & 10 & 15 & 11 & 14 & 8 & 13 & 3 & 5 & 3 & 3.8 & 4.5 \\
\hline $\begin{array}{l}\text { The cooperation and networking of citizens } \\
\text { with research institutions }\end{array}$ & 0 & 5 & 15 & 13 & 18 & 13 & 12 & 7 & 4 & 4 & 1 & 4.2 & 3.3 \\
\hline $\begin{array}{l}\text { The development of new methods to involve } \\
\text { citizens in research (including apps etc.) }\end{array}$ & 0 & 4 & 8 & 10 & 13 & 11 & 10 & 7 & 14 & 12 & 1 & 5.1 & 3.9 \\
\hline $\begin{array}{l}\text { The acceptance of science on the part of } \\
\text { the citizens }\end{array}$ & 0 & 3 & 3 & 4 & 9 & 12 & 17 & 8 & 11 & 16 & 3 & 5.1 & 4.8 \\
\hline $\begin{array}{l}\text { The knowledge transfer from science } \\
\text { to citizens }\end{array}$ & 0 & 4 & 9 & 5 & 12 & 16 & 13 & 12 & 12 & 8 & 2 & 5.1 & 3.5 \\
\hline $\begin{array}{l}\text { The variety of citizen science activities } \\
\text { available to the public }\end{array}$ & 0 & 1 & 8 & 12 & 12 & 10 & 10 & 15 & 8 & 8 & 5 & 5.3 & 3.9 \\
\hline
\end{tabular}

11-point scale starting from 0 Percent to 100 Percent. $n=97$.

\section{References}

1. West, S.; Pateman, R. How Could Citizen Science Support the Sustainable Development Goals? Policy Brief; Stockholm Environment Institute: York, UK, 2017; Available online: https:/ /www.sei.org/publications / citizen-science-sustainable-development-goals / (accessed on 17 August 2020).

2. Fraisl, D.; Campbell, J.; See, L.; Wehn, U.; Wardlaw, J.; Gold, M.; Moorthy, I.; Arias, R.; Piera, J.; Oliver, J.L.; et al. Mapping Citizen Science Contributions to the UN Sustainable Development Goals. Sustain. Sci. 2020. [CrossRef]

3. Fritz, S.; See, L.; Carlson, T.; Haklay, M.; Oliver, J.L.; Fraisl, D.; Mondardini, R.; Brocklehurst, M.; Shanley, L.A.; Schade, S.; et al. Citizen science and the United Nations Sustainable Development Goals. Nat. Sustain. 2019, 2, 922-930. [CrossRef]

4. Shulla, K.; Filho, W.L.; Sommer, J.H.; Lange Salvia, A.; Borgemeister, C. Channels of collaboration for citizen science and the sustainable development goals. J. Clean. Prod. 2020, 264. [CrossRef]

5. German Citizen Science-Platform. Available online: https://buergerschaffenwissen.de (accessed on 17 December 2020).

6. Austrian Citizen Science-Platform. Available online: https://www.citizen-science.at/ (accessed on 17 December 2020). 
7. Swiss Citizen Science-Platform. Available online: https://www.schweiz-forscht.ch/ (accessed on 17 December 2020).

8. European Citizen Science-Platform. Available online: https:/ / eu-citizen.science/ (accessed on 17 December 2020).

9. Sauermann, H.; Vohland, K.; Antoniou, V.; Balázs, B.; Göbel, C.; Karatzas, K.; Mooney, P.; Perelló, J.; Ponti, M.; Samson, R.; et al. Citizen Science and sustainability transitions. Res. Policy 2020, 49, 103978. [CrossRef]

10. Josephsen, L. Approaches to the Implementation of the Sustainable Development Goals—Some Considerations on the Theoretical Underpinnings of the 2030 Agenda; Economics Discussion Papers, No. 2017-60; Kiel Institute for the World Economy (IfW): Kiel, Germany, 2017; Available online: http:/ / www.economics-ejournal.org/economics/discussionpapers/2017-60 (accessed on 17 December 2020).

11. Shirk, J.L.; Ballard, H.L.; Wilderman, C.C.; Phillips, T.; Wiggins, A.; Jordan, R.; McCallie, E.; Minarchek, M.; Lewenstein, B.V.; Krasny, M.E.; et al. Public participation in scientific research: A framework for deliberate design. Ecol. Soc. 2012, 17, 29. [CrossRef]

12. Roczen, N.; Kaiser, F.G.; Bogner, F.X.; Wilson, M. A competence model for environmental education. Environ. Behav. 2014, 46, 972-992. [CrossRef]

13. Brossard, D.; Lewenstein, B.; Bonney, R. Scientific knowledge and attitude change: The impact of a citizen science project. Int. J. Sci. Educ. 2005, 27, 1099-1121. [CrossRef]

14. Moczek, N. Freiwilliges Engagement für Citizen Science-Projekte im Naturschutz: Konstruktion und Validierung eines Skalensystems zur Messung motivationaler und organisationaler Funktionen, 1st ed.; Pabst Science Publishers: Lengerich, Germany, 2019.

15. Schleicher, K.; Schmidt, C. Citizen Science in Germany as Research and Sustainability Education: Analysis of the main forms and foci and its relation to the Sustainable Development Goals. Sustainability 2020, 12, 6044. [CrossRef]

16. Theobald, E.J.; Ettinger, A.K.; Burgess, H.K.; DeBey, L.B.; Schmidt, N.R.; Froehlich, H.E.; Wagner, C.; Hille Ris Lambers, J.; Tewksbury, J.; Harsch, M.A.; et al. Global change and local solutions: Tapping the unrealized potential of citizen science for biodiversity research. Biol. Conserv. 2015, 181, 236-244. [CrossRef]

17. Knowledge for Change: Citizen Science SDG Conference. Available online: https:/ /www.museumfuernaturkunde.berlin/en/ museum/events/knowledge-change-citizen-science-sdg-conference (accessed on 17 December 2020).

18. Leiner, D.J. SoSci Survey Version 3.1.06-i [Computer Software]. 2016. Available online: https://www.soscisurvey.de (accessed on 12 February 2020).

19. Schot, J.; Steinmueller, W.E. Three frames for innovation policy: R\&D, systems of innovation and transformative change. Res. Policy. 2018, 47, 1554-1567. [CrossRef]

20. Who is Being Left Behind in COVID-19 Data? United Nations World Data Forum Blog. Available online: https:/ /unstats.un.org/ unsd/undataforum/blog/who-is-left-behind-in-COVID-19-data/ (accessed on 17 December 2020).

21. Salvia, A.L.; Leal Filho, W.; Brandli, L.L.; Griebeler, J.S. Assessing research trends related to Sustainable Development Goals: Local and global issues. J. Clean. Prod. 2019, 208, 841-849. [CrossRef]

22. Sustainable Development Goals Knowledge Platform. Global Follow-Up and Review of the 2030 Agenda for Sustainable Development. Available online: https:/ / sustainabledevelopment.un.org/hlpf/follow-up (accessed on 17 December 2020).

23. Frigerio, D.; Richter, A.; Per, E.; Pruse, B.; Vohland, K. Citizen Science in the Natural Sciences. In The Science of Citizen Science; Springer: Cham, Switzerland, 2021; pp. 79-96. 